\title{
FROM DRIVER MODELLING TO HUMAN MACHINE INTERFACE PERSONALISATION
}

\author{
M. Panou ${ }^{a}$, N. Cacciabue $^{b}$, P. C. Cacciabue $^{c}$, E. Bekiaris $^{a}$ \\ ${ }^{a}$ Hellenic Institute of Transport, 6th km. Charilaou-Thermi Road, 57001 Thermi, Greece. \\ ${ }^{b}$ KITE Solutions - V. Labiena 93, 21014 Laveno (VA), Italy. \\ ${ }^{c}$ EC, Joint Research Centre - V. E. Fermi 1, 21020 Ispra (VA) Italy.
}

\begin{abstract}
The model of Driver-Vehicle-Environment will be one of the essential elements in order to personalise the design of Human-Machine Interfaces (HMI) of ADAS/IVIS systems in modern vehicles. In this paper the fundamental correlations for developing such models are discussed in some detail. Copyright () 2005 IFAC
\end{abstract}

Keywords: Advance Driver Assistance Systems, In-Vehicle Information Systems, Intelligent Agents, HMI personalisation, Cognitive Driver model.

\section{INTRODUCTION}

The development of concepts for safe and efficient human-machine interaction is a key step towards the realisation of intelligent road vehicles with higher safety and value-added services.

The general recommended strategy for safety on European roads is outlined further in the eSafety report, issued in 2002 by the eSafety Working Group (European Commission, 2002). In this report, it is stated that "human-machine interaction with increasingly more complex in-vehicle systems is a major concern" and the area is identified as one of the main building blocks for integrated safety.

The European Integrated Project AIDE (Adaptive Integrated Driver-vehicle InterfacE - IST-1-507674IP) has been explicitly planned to address the key HMI issues identified in the eSafety report. In particular, one of the main sub-goals of the AIDE IP is to perform theoretical analyses and field studies aimed at predicting human behaviour and error, specifically related to the interaction with ADAS
(Advanced Driver Assistance Systems) and IVIS (In-Vehicle Information Systems).

The way to tackle these issues is to apply a model of human behaviour that enables to predict behaviour and is sufficiently adaptive to individual characteristics so as to personalise the interface between vehicle and driver. The personalisation aspect of the system is as important as the modelling part. This derives from the fact that the enormous diffusion of road vehicles and the diversity of drivers do not allow the generalisation of driving behaviours, styles and attitudes that is usually assumed in other transportation domains.

Modelling of driver behaviour has a long tradition including control-theoretic models of operational performance (e.g. McRuer and Weir, 1969), cognitively-oriented models of risk (e.g. Summala, 1988) and hierarchical models, incorporating behaviours at different levels (e.g. operational, tactical and strategical), (e.g. Michon, 1985). However, models specifically aimed at predicting behavioural effects of introducing IVIS and ADAS functions are rare and a comprehensive understanding of the underlying mechanisms is 
lacking (Smiley, 2000). Computer simulations have been successfully used for predicting human behaviour in the aviation domain (e.g. Cacciabue et al., 1992). There have been few efforts on applying these techniques in the domain of driver-vehicle interaction. One exception is the recent work on simulating the effects of IVIS on driving behaviour (Salvucci, 2001).

This paper describes the initial steps toward the development of the model of driver behaviour and adaptation assessment that are designed for implementation in future vehicles.

\section{BEHAVIOURAL ADAPTATION}

Studying the integration of a new aid to driving activity and identifying behavioural changes entails selecting the relevant indicators for revealing the changes likely to take place in drivers' activity (Saad, 2002). Many studies highlight the circumstantial requirements of driving assistance according to the dynamics of various environmental conditions and the drivers' motives, objectives and intentions in these conditions. As an example "Driving Style" seems to play a role in the overall frequency of support system usage, the magnitude of some behavioural changes when using the system as well as in the level of acceptance of the assistance provided. Moreover, some individual characteristics such as "Sensation Seeking" or "Locus of Control" seems to amplify the behavioural changes observed when driving with the driving support systems.

With respect to the temporal factors affecting behavioural adaptation, the variables can be organised according to specific phases of long-term effects. In particular, two main phases may be considered, namely:

- Learning and Appropriation Phase: The driver discovers the system, learns how it operates, identifies the precise limits of its competence and delimits its domains of utility. This learning process is assumed to be crucial for the drivers representation of the system, the confidence he/she has (and ought to have) in it and its optimal use.

- Integration Phase: The driver, through his/her experiences using the system in different road situations, reorganises his/her activity by integrating the system in the management of the overall driving task.

\section{ELECTRONIC DRIVER-VEHICLE- ENVIRONMENT MODEL}

The Electronic Driver-Vehicle-Environment (EDVE) model and simulation aim at representing the DVE interaction in a simple and smooth running way, which retains the essential correlations between the fundamental independent variables and enables to predict driver behaviour in dynamic and rapidly changing conditions. The model focuses on the way in which a process of interaction is influenced and how it can be simulated with respect to a single journey.

\subsection{General architecture of E-DVE model}

For AIDE project's development the architecture adopted to represent the interactions between Driver, Vehicle and Environment can be framed in a generic architecture describing the way in which humans interact with the world and systems around them, called SHELL (Edwards, 1988). The SHELL structure (Figure 1) describes the connections existing between humans, defined Liveware (L), and other elements of the working environments, namely:

1. The physical sources, such as equipment, materials, interfaces, and machines, which may be termed Hardware (H): L-H interactions.

2. Rules, regulations, laws, procedures, customs, practices and habits governing the way in which a plant or a machine are operated, called Software (S): L-S interactions.

3. Social, physical and technical aspects of working contexts, which may be called Environment (E): L-E interactions.

4. Direct communications and exchange of information of the driver with other human beings, such as passengers or other drivers in different vehicles, which is termed Liveware (L): $L-L$ interactions.

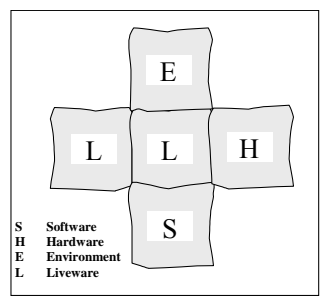

Figure 1: The SHELL Configuration.

The SHELL architecture can be utilised to represent the different variables that affect the DVE model. Moreover, in order to capture the crucial dimension time, affecting the process of driving in different conditions and situations, a further subdivision can be considered at three discrete time levels:

- Static variables, which account for variables that do not change over the journey. Examples of these are: age of driver, gender, personality, procedures, etc.

- Quasi-Static variables, which account for the phenomena and interactions that may change during a journey even though these changes are slow and foreseeable. Examples of quasi-static variables are: attitudes, behavioural adaptation, etc.

- Dynamic variables, which account for the events and phenomena that occur during a journey and may be affected by the evolution of 
the DVE interaction itself or may not be anticipated Examples of dynamic variables are: workload, stress, traffic conditions, type of roads, weather, etc.

A table can be devised that contain this preliminary structure and can be updated according to the development of different models and findings from experiments and field studies (Table I).

Table I. Variables according SHELL structure

\begin{tabular}{|c|c|c|c|}
\hline SHELL & $\begin{array}{c}\text { Static } \\
\text { Variables }\end{array}$ & $\begin{array}{c}\text { Quasi -static } \\
\text { Variables }\end{array}$ & $\begin{array}{l}\text { Dynamic } \\
\text { Variables }\end{array}$ \\
\hline $\begin{array}{l}\text { Liveware } \\
\boldsymbol{L}\end{array}$ & $\begin{array}{l}\text { - Age, } \\
\text { - Gender, } \\
\text { - Personality }\end{array}$ & $\begin{array}{ll}\text { - } & \text { Expertise } \\
\text { - } & \text { Attitudes } \\
\text { - } & \text { Adaptation }\end{array}$ & $\begin{array}{ll}\text { - } & \text { Workload } \\
\text { - } & \text { Distraction } \\
\text { - } & \text { Haste }\end{array}$ \\
\hline $\begin{array}{c}\text { Liveware } \\
\text { Software } \\
\boldsymbol{L}-\boldsymbol{S}\end{array}$ & $\begin{array}{l}\text { - Training, } \\
\text { - Driving proced. } \\
\text { - Driving rules }\end{array}$ & 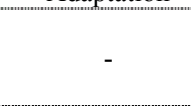 & trow \\
\hline $\begin{array}{c}\text { Liveware } \\
\text { Liveware } \\
\text { L-L }\end{array}$ & - & - Passengers & $\begin{array}{ll}\text { - } & \text { Other } \\
\text { drivers }\end{array}$ \\
\hline $\begin{array}{l}\text { Liveware } \\
\text { Environ. } \\
\boldsymbol{L}-\boldsymbol{E}\end{array}$ & $\begin{array}{l}\text { - National } \\
\text { culture }\end{array}$ & $\begin{array}{ll}\text { - } & \text { Weather } \\
\text { conditions } \\
\text { - } \\
\text { Types of } \\
\text { roads }\end{array}$ & $\begin{array}{l}\text { - Environment } \\
\text { Variables }\end{array}$ \\
\hline $\begin{array}{c}\text { Liveware } \\
\text { Hardware } \\
\boldsymbol{L}-\boldsymbol{H}\end{array}$ & Type of vehicle & $\begin{array}{l}\text { - } \begin{array}{l}\text { State of } \\
\text { vehicle }\end{array}\end{array}$ & $\begin{array}{l}\text { - } \quad \text { Vehicle } \\
\text { variables }\end{array}$ \\
\hline
\end{tabular}

\subsection{Time frame of Model E-DVE}

The time distribution of the model considers a single time step prediction system that is continuously updated with the real data resulting for the actual behaviour of the overall driving environment.

The behaviour of the Driver can be affected by two types of conditions: Subjective Conditions and Objective Conditions. It is assumed that Subjective Conditions depend on: Risk Taking $\left(R T_{D}\right)$; Complacency $\left(C_{D}\right)$; and Situation Awareness $\left(S A_{D}\right)$. Objective Conditions are instead correlated to: Risk Level $\left(R L_{D}\right)$; and Performance Limitations $\left(P L_{D}\right)$. These conditions are the real bottle neck of the model, as they need to be evaluated and correlated to real measurable variables. The functions that describe these correlations may be:

$R T_{D}=f(L, L-E, L-H)$

$C_{D}=f_{\text {self }}(L) ; \quad g_{\text {aut }}(L, L-H) ; \quad l_{\text {veh }}(L, L-H)$

$S A_{D}=f_{\text {percep. }}(L, L-E, L-H) ; g_{\text {interp. }}(L, L-E, L-H)$

$R L_{D}=f_{\text {Driver }}(L, L-E, L-H)$

$P L_{D}=f_{\text {Driver }}(L, L-E)$

\section{SIMPLIFIED MODEL OF DRIVER}

\subsection{Assumptions and initial hypotheses}

The basic assumption made for the development of the model of the driver, is that the driver is essentially performing a set of actions that are well known and familiar, according to his/her experience. As the driving process is very dynamic, these actions are continuously selected from a vast repository of knowledge (Knowledge Base) by a diagnostic process. Consequently, the processes of diagnosis and interpretation of acquired information become crucial for the dynamic sequencing of driver's activity.

The model of the driver adopted is based on a very simple approach that assumes that behaviour derives from a cyclical sequence of four cognitive functions, namely: Perception, Interpretation, Planning and Execution (PIPE). This model is not sequential, as the Execution function, i.e. the manifested form of behaviour, may result from several iterations (cyclical) of the other functions. Moreover, in agreement with the initial hypothesis, the Planning function, is usually bypassed by the "automatic" selection of familiar frames of knowledge that are associated with procedures or sets of several actions aiming at the fulfilment of the goal of a frame. This function is however important as it becomes effective in unknown situations or in the case of novice drivers, when "simpler" frames, based on single actions or on a limited sequence of very simple/familiar actions, are called into play to deal with the situation. These four cognitive functions can be associated to either sensorial or cognitive processes, and are activated according to certain rules or conditions (Table II).

Table II. Driver Model and rules for implementation

\begin{tabular}{|c|c|c|}
\hline $\begin{array}{l}\text { PIPE Driver } \\
\text { Model }\end{array}$ & Type of Process & $\begin{array}{l}\text { Rules or governing } \\
\text { assumptions }\end{array}$ \\
\hline $\begin{array}{l}\text { Perception of } \\
\text { signals }\end{array}$ & $\begin{array}{l}\text { Sensorial } \\
\text { process }\end{array}$ & $\begin{array}{l}\text { - Haptic } \\
\text { - Visual } \\
\text { - Aural }\end{array}$ \\
\hline Interpretation & $\begin{array}{l}\text { Cognitive } \\
\text { process }\end{array}$ & $\begin{array}{l}\text { - Similarity Matching } \\
\text { - Frequency Gambling }\end{array}$ \\
\hline Planning & $\begin{array}{l}\text { Cognitive } \\
\text { process }\end{array}$ & - Inference/reasoning \\
\hline Execution & $\begin{array}{l}\text { Behavioural } \\
\text { process }\end{array}$ & $\begin{array}{l}\text { - Performance of selected } \\
\text { actions / iterations }\end{array}$ \\
\hline
\end{tabular}

Perception of Signals

Signals can be perceived when the threshold of their content (either haptic, aural, or visual) is above certain limits. The following correlations apply for simulating a perception process:

$$
\begin{array}{llll}
\text { Haptic signal }(0 \leq \mathrm{Hp} \leq 1): & H p_{\text {sign }}=f_{\text {signal }}(H) \\
\text { Visual } & \text { signal }(0 \leq \mathrm{Vi} \leq 1): & V i_{\text {sign }}=g_{\text {signal }}(H) \\
\text { Aural signal }(0 \leq \mathrm{Au} \leq 1): & A u_{\text {sign }}=l_{\text {signal }}(H)
\end{array}
$$

\section{Interpretation}

The interpretation of perceived information is governed by two interconnected "primitives of cognition", which are in essence equivalent to conservation principles. They are called Similarity Matching (SM) and Frequency Gambling (FG) and are derived from theories of cognition of Reason (1990). In short, this theory claims that in order to perform a diagnosis human beings process the perceived information firstly by matching it with 
their acquired and stored knowledge, by means of the Similarity Matching principle. Then, amongst the various possible alternative solutions (frames) that match the perceived information, they select only one frame ("active frame"), on the basis of their past experience or frequency of encounter, i.e. by the Frequency Gambling principle.

Each Frame is associated with a specific tag (or coefficient) of frequency of encounter:

$$
F G_{c o}=\alpha(L, L-E, L-S, L-H, L-L) \quad 0 \leq \alpha \leq 1
$$

Each Frame is characterised by a number of Attributes that enable the matching of the perceived situation with the frame. These attributes can be numerical or logical expressions according to the type of information dealt with. Examples of Attributes are: "presence of traffic light", "speed of vehicle", "traffic conditions", "signals from other driver":

$$
\begin{aligned}
& A_{1_{F 1}}=f_{1}(L, L-E, L-H, L-S, L-L) \\
& \cdots \cdots \cdots \\
& A_{N_{F 1}}=f_{N}(L, L-E, L-H, L-S, L-L)
\end{aligned}
$$

The overall structure of a Frame is more complex and contains, in addition to the Attributes and the FG tag, the list of actions that are carried out and the goal that is associated with the Frame. A detailed description of the Frames is reported in $\S 4.2$.

\section{Planning}

In order to keep the DVE model as simple as possible, it will be assumed that Planning takes places only in the presence of unfamiliar situations. When Planning is required, the process generates a sequence of simple frames made of elementary actions and the model very rapidly cycles through the cognitive functions PIPE, generating, planning and performing such simple actions from equally elementary frames.

\section{Execution}

The Execution function implies a sequence of actions carried out on the vehicle either by interacting with the interfaces or with the controls. The activity can be formalised by identifying the type of action to be carried out and then the mode of action. In more detail, the type of actions defines the physical process that is carried out. Examples of types of actions are "listen for the alarm", "look at speed indicator", "change gear", "steer gently to the left", "brake violently". The mode in which the action type is implemented associates to each type a very specific and quantifiable values. According to the overall DVE model characteristics, different types and modes of actions can be envisaged:

- If the DVE model is based on a numerical quantification approach, then examples of action modes are: "time of listening of alarm", "time of observation of the speed indicator", "gear-up one", "Steer $25^{\circ}$ left", "apply a force of $\alpha \mathrm{KN}$ to the break pedal", etc.

- If the DVE model is based on a mixed approach of quantitative and logical expressions, such as "fuzzy correlations", then the examples of actions modes are: "listen for aural input", "look at indicators:, "adapt speed to achieve goal", "keep with lane and road boundaries", "break violently/gently", etc.

\subsection{Basic Structure of Frames}

\section{Types of Frames}

The core of the Driver model lies with the Frames. Two types of Frames are envisaged: Quasi-static Frame, and Dynamic Frames. Quasi-static Frames are relatively simple and serve the objective of setting reference values for the subjective and objective conditions (Table III): reach destination, normal roads, motorways, and city/village. They are characterised by attributes associated mainly with road type and traffic. During a journey it is possible that a change of destination and/or road conditions occurs. Frequency tags are set to 1 as these Frames

\begin{tabular}{|c|c|c|c|c|c|}
\hline $\begin{array}{c}\text { Q-S } \\
\text { Frame }\end{array}$ & Goal & $\begin{array}{l}\text { FG } \\
\text { Tag }\end{array}$ & & Attrib. & Activity \\
\hline $\begin{array}{l}\text { Reach } \\
\text { destin. }\end{array}$ & $\begin{array}{l}\text { Drive to } \\
\text { destination }\end{array}$ & 1 & $\checkmark$ & - & $\begin{array}{l}\text { - Initial values for } \\
\text { Subj./Obj. Con. }\end{array}$ \\
\hline $\begin{array}{l}\text { Normal } \\
\text { road }\end{array}$ & $\begin{array}{l}\text { On Normal } \\
\text { road }\end{array}$ & 1 & & $\begin{array}{l}\text { Traffic } \\
\text { Road type }\end{array}$ & $\begin{array}{l}\text { - Ref. values for } \\
\text { Subj./Obj. Con. }\end{array}$ \\
\hline Motorway & $\begin{array}{l}\text { Drive on } \\
\text { Motorway }\end{array}$ & 1 & $\begin{array}{l}\checkmark \\
\checkmark\end{array}$ & $\begin{array}{l}\text { Traffic } \\
\text { Road type }\end{array}$ & $\begin{array}{l}\text { - Ref. values for } \\
\text { Subj./Obj. Cond. }\end{array}$ \\
\hline City/vill. & $\begin{array}{l}\text { Drive on } \\
\text { City/village }\end{array}$ & 1 & $\begin{array}{l}\checkmark \\
\checkmark\end{array}$ & $\begin{array}{l}\text { Traffic } \\
\text { Road typ } \epsilon\end{array}$ & $\begin{array}{l}\text { - Ref. values for } \\
\text { Subj./Obj. Cond. }\end{array}$ \\
\hline
\end{tabular}
are mutually exclusive.

Table III. Quasi-Static Frames

Dynamic Frames contain the overall process of driving that is implemented in a typical journey from starting the vehicle to stopping it having reached destination. The model of the Driver is composed of many Dynamic Frames. Each Frame is associated with an overall goal, a frequency tag, several attributes, and a set of actions that can be performed in parallel or in sequence to reach the objective. Examples of Dynamic Frames are: Within traffic, At traffic light, Controlled areas, Risk situations, Accident Risk situation, Secondary task.

\section{Modelling Activity}

The complexity of a Frame increases with the experience and expertise of a driver. A Frame is made of a series of actions that enable to fulfil the goal and are organised in a flowchart structure containing nodes and decision points. The simulation follows a flowchart to determine the outcome of every action that is performed. Therefore, each action of the driver is associated with a specific action execution flowchart. The path that is taken through this flowchart describes the decisions made by the virtual driver that lead to the production of a particular action. 


\section{Time Sequence}

At time $t_{i}$ the following quantities are evaluated according to the above equations of $R T_{D}\left(t=t_{i}\right)$, $C_{D}\left(t=t_{i}\right), \quad S A_{D}\left(t=t_{i}\right), \quad R L_{D}\left(t=t_{i}\right), \quad P L_{D}\left(t=t_{i}\right)$. On the basis of these variables, the Driver Impairment Level (DIL) is evaluated. If the DIL falls below a certain threshold, then the Task/Activity associated with the active Dynamic Frame can be carried out. Moreover, according to the value of the DIL the manifestation of behaviour can be associated with inadequate behaviour, total impairment, search for a new activity, etc. The following requirement is thus needed in order to manage the time evolution of a Driver Vehicle interaction:

$$
\operatorname{DIL}\left(t=t_{i}\right)=\frac{W_{R L} \cdot R L_{D}\left(t=t_{i}\right)+W_{P L} \cdot P L_{D}\left(t=t_{i}\right)}{W_{R T} \cdot R T_{D}\left(t=t_{i}\right)+W_{C} \cdot C_{d}\left(t=t_{i}\right)+W_{S A} \cdot S A_{D}\left(t=t_{i}\right)}
$$

Where:

$W_{R L}=$ Weight of Risk Level

$W_{P L}=$ Weight of Performance Limitation

$W_{R T}=$ Weight of Risk Taking

$W_{C}=$ Weight of Complacency

$W_{S A}=$ Weight of Situation Awareness

As an example the following rule applies:

- If $0 \leq D I L\left(t=t_{i}\right) \leq D I L_{1}=>$ no effects.

- If $D I L_{1}<D I L\left(t=t_{i}\right) \leq D I L_{2}=>$ error making.

- If $D I L_{2}<D I L\left(t=t_{i}\right) \leq 1=>$ impaired performance.

Where:DIL $L_{1}=$ Max. Value of DIL for no effects on performance; and $D I L_{2}=$ Max. Value of $D I L$ for inadequate performance. The evaluation of these parameters and weights demands extended experimental work and field observation.

\section{ERROR GENERATION MECHANISMS}

The error generation mechanism is related to the Driver Impairment Level, the dynamic interaction process of the three elements of the DVE model, and to the "Failure Mode and Effect Analysis" (FMEA) process carried out by the manager of the DVE simulation (Figure 2).

At each time step of the simulation $\left(t=t_{i}\right)$, or at each time interval of the DVE interaction, the overall contribution of the three components of the DVE model is evaluated by extracting the variables that influence the DIL. Then the simulation manager firstly performs the FMEA and identifies whether the Driver is able to continue the ongoing activity $\left(0 \leq D I L\left(t=t_{i}\right) \leq D I L_{1}\right)$, or performs inadequately or is impaired $\left(D I L>D I L_{1}\right)$. In particular, the Effect Analysis selects the actual effect that should be shaping the activity in the following time step.

This process of FMEA discussed for the Diver model can be replicated for the models of the Vehicle and Environment in the case of a full simulation of the DVE interaction, thus generating possible inadequate or improper performances of the vehicle or risky situation associated with the environment. In a real situation the dynamic evolution of the Vehicle and Environment are recorded in reality and can be easily derived.

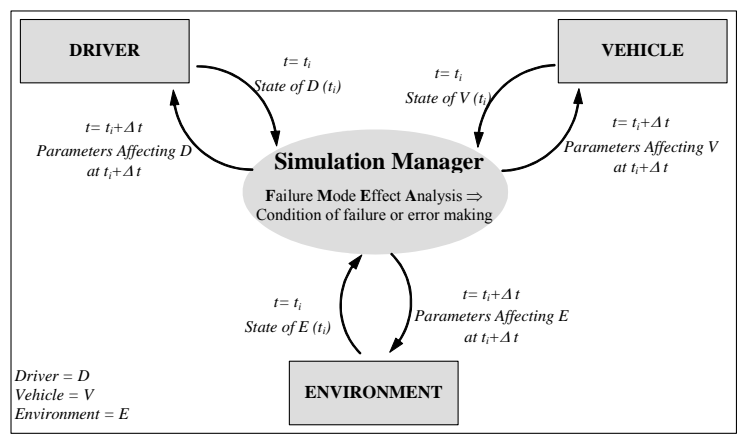

Figure 2. Architecture of DVE Model

A number of requirements are needed in order to define the consequences of different degrees of impairment. As an example for Perception the following correlations may be adopted:

If $0 \leq D I L\left(t=t_{i}\right) \leq D I L_{1}$ then:

Haptic signals can be perceived if $H p_{\text {sig }} \geq 0.25$

Visual signals can be perceived if $V i_{\text {sig }} \geq 0.25$

Aural signals can be perceived if $A u_{\text {sig }} \geq 0.25$

If $D I L_{1}<D I L\left(t=t_{i}\right) \leq D I L_{2}$, performance inadequate:

Haptic signals can be perceived if $H p_{\text {sig }} \geq 0.75$

Visual signals can be perceived if $V i_{\text {sig }} \geq 0.75$

Aural signals can be perceived if $A u_{s i g} \geq 0.75$

If $D I L_{2}<D I L\left(t=t_{i}\right) \leq 1$, performance totally impaired and no new signals perceived.

\section{MODEL-BASED HMI PERSONALISATION}

The above model needs to be supplied with actual data on driver status (i.e. age, gender, experience), his/her intentions and behavioural context (i.e. reason for driving) and, actual driving behaviour (i.e. position in the lane, headway, etc.). Such data are provided to the model by a multi-sensorial system, through the DVE module. Once the data is received and processed, the DVE model outputs the DIL level. Of course, it is not enough to perceive the driver's impairment level, or to know the traffic situation. The system needs to convey the required services to the driver, as well as to issue the necessary warnings. These are influenced by the driver's explicit preferences, his/her impairment level and his/her residual abilities.

The Driver's Characteristics Module (DCM) is the module that intervenes between the DVE and the actual HMI communications, in order to provide guidance on how, when and what level of service to provide to the driver. Similarly to the DVE model, this module also utilizes three types of variables for HMI personalisation:

- Static variables, that include driver age, gender, driving experience (parameters which self-evolve with time), etc. 
- Quasi-static variables, mainly related to the driver's intentions as defined by the purpose of the journey (i.e. travelling as commuter, tourist, businessman, for work or for pleasure, etc.).

- Dynamic variables, that are related to the environment (time of day, weather conditions, type of road, traffic, etc.), the driver's own status, directly estimated by the use of the DIL degree, provided by the driver model, and the driver's perceived preferences and residual abilities.

Driver preferences and residual abilities are estimated by monitoring the particular driver's use of ADAS/IVIS services. For example, based upon data gathered over long periods of driving and under different conditions, the driver's reaction time is estimated and clustered into 4 levels: very slow, (i.e. above $1.3 \mathrm{sec}$ ), slow (above $1 \mathrm{sec}$ ), average (0.8-1 $\mathrm{sec}$ ) and quick (below $0.8 \mathrm{sec}$ ). The driver's average lane position and change (based upon Time to Line Crossing - TLC measurements) are also estimated. Other preferences, such as provision of navigation and route guidance by map or vectors, will be estimated by monitoring the driver's own selections through a series of system usages.

These three variable types will be handled by two different Agents. Initially, a User's Profile Configuration Agent will support different "types of users". The users themselves will choose his/her type, residual abilities and preferences on posture, interface elements, etc. Actions will be taken to secure user's sensitive personal information, a proper, in-vehicle interface for input of this profile by the user will be also developed (user-friendly, cost-effective). Then, a Customisation Agent will monitor the user's driving behaviour and preferences/actions, by keeping and processing the user's driving record, i.e. average position in the lane, average headway, typical speeding and braking pattern, preferred seating position, average use of radio and mobile phone, other services, like navigation, requested often, etc. The self-built user profile will be always possible to be reviewed and changed by the user.

$J A D E$, the Java Agent Development framework will be the basis for building FIPA-compliant interoperable Agents. Such a framework ensures that Agents aspects, such as message transport, encoding, parsing, Agent life cycle, are dealt, while it utilises the FIPA ACL standard Agent language. The data will be stored in a driver smart card (encoded), to be used also in other equipped cars.

It should be noticed that the connection between the DVE model and the DCM may be also two directional. The DVE model may better estimate the driver's impairment level if it considers the difference between the current driver behaviour at the Execution level (see PIPE model at section 4.1) and his/her "average" or "manual" Execution level. The building of this link is also under investigation.

\section{CONCLUSION}

The E-DVE model in its current formulation may be rather incomplete and does not cover a number of variables that could become very important after the performance of the experiments on learning, appropriation and long term behavioural adaptation. However, the present correlations are sufficiently generic and flexible to accommodate new equations and variables in case the results of experiments demand modification of the present correlations.

\section{ACKNOWLEDGEMENTS}

The authors are indebt to the researchers and colleagues of the Project AIDE for their support and collaboration in the development of this paper.

\section{REFERENCES}

Cacciabue P.C., Cojazzi G., Hollnagel E., Mancini S. (1992). Analysis and Modelling of Pilot-Airplane Interaction by an Integrated Simulation Approach. Proc. 5th IFAC/IFIP/IFORS/IEA Symposium on Analysis, Design and Evaluation of MMS. The Hague, 9-11 June. pp. 227-234, Pergamon, Oxford.

Edwards, E. (1988). Introductory overview. In E. L. Wiener, and D. C. Nagel (Eds.), Human Factors in Aviation, Academic Press, San Diego, CA. pp. 3-25. European Commission (2002). Final Report of the eSafety Working Group on Road Safety. Information Society Technologies, November 2002

McRuer, D and Weir, D. (1969). Theory of Manual Vehicular Control. Ergonomics, 12, 599-633.

Michon, J. A. (1985). A Critical View of Behaviour Models. What do we know, what should we do? In L. Evans and R. Schwing (Eds.) Human Behaviour and Traffic Safety. New York: Plenum Press.

Reason, J. (1990). Human Error. Cambridge University Press, Cambridge, UK.

Saad, F. (2002). Ergonomics of the driver's interface with the road environment : the contribution of Psychological research. In R. Fuller \& J.A. Santos (Eds), Human factors for highway engineers, 23-41, Pergamon, Oxford.

Salvucci, D. D. .(2001). Predicting the effects of incar interface use on driver performance: An integrated model approach. IJ-HCS, 55, 85-107.

Smiley, A. (2000). Behavioural Adaptation, Safety and Intelligent Transportation Systems. TRR, Vol. 1724, 47-51

Summala, H. (1988). Risk Control is not Risk Adjustment: The Zero-risk Theory of Driver Behaviour and its Implications. Ergonomics, 31, 491-506. 